\title{
Design of Subject-based Community Model by Linkage Heterogeneous Content: Focused on Field of Biological Science
}

\author{
Buyoung Ahn ${ }^{1}$, Jiyoung Kim ${ }^{2}$, Chungshick $\mathrm{Oh}^{3}$, and Myungsun Lee ${ }^{1}$ \\ Supercomputing Center ${ }^{1}$, Knowledge Information Center ${ }^{2}$, Information Strategy Team ${ }^{3}$ \\ Korea Institute of Science and Technology Information \\ 335 Gwahangro, Yuseong-gu, Daejeon, Korea
}

\begin{abstract}
Researchers in Korea and elsewhere have carried out a wide variety of important research activities in their respective fields, producing valuable research results. For such diverse research results to be shared and exchanged among researchers working in the same discipline and research subject there needs to be a community environment based on free utilization of information. Against this backdrop, this study seeks to classify and reprocess the referencelfactual content owned by the KISTI (Korea Institute of Science and Technology Information), a state-run distributor of information on science and technology, by the different research subjects. It also seeks to develop and provide a community model based on the concepts of open archiving and open access for the researchers specialized in the related fields of research. This community model is developed focusing on the research results from the field of bioscience, where the most extensive studies are currently being conducted. To develop the community model, this study: (a) surveys the current status of the content owned by KISTI; (b) analyzes the patterns and characteristics of biological scientific content among the KISTI-owned content; and (c) designs a web platform where researchers can freely upload/download research results.
\end{abstract}

Keywords: Community Model, Content Linking, Factual Content, Literature Content, Patent Content, Biological Science

\section{INTRODUCTION}

It is no exaggeration to say that, amid an exponential increase in the volumes of information available, we are now living in a flood of information. A slew of new disciplines are being created, as a growing number of disciplines are converged and interlinked with others, and researchers working on such disciplines are producing countless volumes of research findings. With the development of information technology and the Internet, these research findings (e.g. articles published in academic journals or presented in symposiums, research reports, patents, research notes, seminar presentations, school materials, and articles in newspapers or magazines) are being provided across a wide variety of web portals on science/technology or liberal arts/social sciences.

Researchers seeking to search research findings in a given, specialized field of research, however, find these portals rather inconvenient, as they often end up retrieving unwanted information on other fields of research as well. To address this problem, research has recently been underway on an information service combined with the semantic web, but this new information service has yet to be applied to information service platforms in Korea.

\footnotetext{
This is an excellent paper selected from the papers presented at ICCC 2009.

* Corresponding author. E-mail : ahnyoung@kisti.re.kr

Manuscript received Apr. 20, 2010 ; accepted Sep. 06, 2010
}

Hence this paper designs the community model based on the subjects in the field of bioscience, applying the concept of the open archive and the open access using literature, facts, and patent contents already established by KISTI focusing on the bioscience field where there are many on-going researches recently.

\section{CURRENT STATUS OF KISTI CONTENT}

\subsection{Literature Content}

Literature content which is collected, processed, and built by KISTI services about 60 million of academic papers, research reports, and the theses for degree. Theses' database provides bibliography of the domestic/oversea journals \& conferences and links it to the information of original electronic text.

Table 1. Status of construction of the literature content

\begin{tabular}{|c|l|l|r|}
\hline Field & \multicolumn{1}{|c|}{ Database } & Period & \multicolumn{1}{c|}{ Number } \\
\hline \multirow{4}{*}{ Journal } & Korean journal & $1948^{\sim}$ & 478,922 \\
\cline { 2 - 4 } & English journal & $1991^{\sim}$ & $39,529,281$ \\
\cline { 2 - 4 } & $\begin{array}{l}\text { China, Japan } \\
\text { journal }\end{array}$ & $2003^{\sim}$ & $2,621,927$ \\
\hline \multirow{2}{*}{ Proceedings } & Korean proceedings & $1972^{\sim}$ & 213,868 \\
\cline { 2 - 4 } & English proceedings & $1993^{\sim}$ & $6,881,628$ \\
\hline INSPEC & Physics, & $1969^{\sim}$ & $9,977,921$ \\
\hline
\end{tabular}




\begin{tabular}{|c|l|c|r|}
\hline \multirow{2}{*}{ FSTA } & Electronics, etc. & & \\
\hline \multirow{2}{*}{ Bibliography } & Food science & $1969^{\sim}$ & 793,567 \\
\cline { 2 - 4 } & Journal & & 63,175 \\
\hline Thesis & Korean thesis & $1945^{\sim}$ & $1,072,406$ \\
\hline \multirow{2}{*}{ Report } & $\begin{array}{l}\text { National R\&D } \\
\text { report }\end{array}$ & $1983^{\sim}$ & 115,911 \\
\cline { 2 - 4 } & NTIS report & $1995^{\sim}$ & 146,421 \\
\hline
\end{tabular}

INSPEC (Information Services for the Physics and Engineering Communities) is a database in physics, electric \& electronics, and computer science provided by IET (The Institution of Engineering and Technology, Great Britain) and FSTA (Food Science \& Technology Abstracts) is the only database in food provided by IFIS (International Food Information Service, Great Britain).

KISTI research report database is from the collection of KISTI selected from the technical reports supported by the budget of USA government and research reports supported by Korean government budget. The theses database is identical to that of National Assembly Library of Korea which collects and accumulates the master and $\mathrm{Ph}$. D. theses announced by the Korean universities and colleges.

\subsection{Factual Content}

Fact information or factual database is the generic concept of the information to the factual data in science and technology fields such as chemical structure, physical characteristics, genetic information, and biodiversity. KISTI built and provides the factual content in the fields of physics, chemicals, bioscience, astronomy, human body, virtual science museum with the support from external experts because the fact data can generated only by the experts of those fields.

Table 2. Status of construction of the factual content

\begin{tabular}{|c|l|l|r|}
\hline Field & \multicolumn{1}{|c|}{ Database } & Period & \multicolumn{1}{c|}{ Number } \\
\hline \multirow{2}{*}{$\begin{array}{c}\text { Physics } \\
\text { /Chemistry }\end{array}$} & ChemDB & $2000^{\sim}$ & $2,579,458$ \\
\cline { 2 - 4 } & ICSD & $1913^{\sim}$ & 93,062 \\
\cline { 2 - 4 } & Plasma & $1995^{\sim}$ & 43,370 \\
\hline \multirow{4}{*}{ Body } & Digital Korean & $2003^{\sim}$ & - \\
\cline { 2 - 4 } & Visible Korean & $2000^{\sim}$ & - \\
\hline \multirow{4}{*}{ Astronomy } & Gene/Protein & $2002^{\sim}$ & $250,000,000$ \\
\cline { 2 - 4 } & Biodiversity & $2000^{\sim}$ & $1,140,000$ \\
\cline { 2 - 4 } & $\begin{array}{l}\text { Luni-Solar } \\
\text { calendar }\end{array}$ & $918^{\sim}$ & \\
\cline { 2 - 4 } & $\begin{array}{l}\text { Ancient } \\
\text { astronomy }\end{array}$ & $2000^{\sim}$ & 3,633 \\
\hline \multirow{3}{*}{$\begin{array}{c}\text { Cyber } \\
\text { museum }\end{array}$} & $\begin{array}{l}\text { Virtual Science } \\
\text { Museum }\end{array}$ & $1999^{\sim}$ & $1,948,740$ \\
\cline { 2 - 4 } & Fossil Museum & $1999^{\sim}$ & 850 \\
\cline { 2 - 4 } & Shell Museum & $1999^{\sim}$ & 950 \\
\cline { 2 - 4 } & $\begin{array}{l}\text { CNIC cyber } \\
\text { museum }\end{array}$ & $2002^{\sim}$ & - \\
\hline
\end{tabular}

\subsection{Patent Content}

KISTI also provides a database service on the patent information focused on USA, Europe, Japan, International, and Korea where more than $80 \%$ of the global patent is owned.

Tab. 3. Status of construction of the patent content

\begin{tabular}{|c|l|r|}
\hline Country & Period & Number \\
\hline Korea & $1947^{\sim}$ & $2,970,872$ \\
\hline USA & $1976^{\sim}$ & $3,710,861$ \\
\hline Japan & $1976^{\sim}$ & $8,019,137$ \\
\hline EU & $1976^{\sim}$ & $1,948,740$ \\
\hline International & $1976^{\sim}$ & $1,486,226$ \\
\hline
\end{tabular}

Korean patent database has 2,970,872 records since 1947 , and those of USA $(3,710,861$ records), Japan $(9,019,137)$, Europe $(1,948,740)$, International $(1,486,226)$ have bibliography, abstracts, patent scope, etc. since 1976[6].

\section{ANALYSIS SCHEMA OF KISTI CONTENT}

\subsection{Literature Content Schema}

Bioscientific themes are classified in KISTI's literature content, among which the most frequently searched database items for articles published in domestic academic journals are presented in Table 4.

Table 4. Schema of literature content

\begin{tabular}{|l|c|}
\hline \multicolumn{1}{|c|}{ Field name } & Code \\
\hline Control Number & CN \\
\hline Title & TI \\
\hline Parrel Title & TIP \\
\hline Author & AU \\
\hline Data Type & \\
\hline Source Type & SO \\
\hline Journal Title & PB \\
\hline Publisher & PY \\
\hline Publish Year & LA \\
\hline Language & VO/IS \\
\hline Volume Issue & PG \\
\hline Pages & SN \\
\hline ISSN & SB \\
\hline ISBN & DC \\
\hline Classification Code & KW \\
\hline Keyword & \\
\hline Copyright & \\
\hline Source Access Path \& Right & \\
\hline
\end{tabular}

\subsection{Factual Content Schema}

KISTI's factual content includes biological information and biodiversity information. Table 5 shows the components of Genbank, a database on genetic information that is the most widely used around the world.

Table 5. Schema of Genbank content

\begin{tabular}{|c|c|}
\hline Field name & Code \\
\hline Locus & LO \\
\hline
\end{tabular}




\begin{tabular}{|l|c|}
\hline Definition & DE \\
\hline Accession & AC \\
\hline Version & VE \\
\hline Keywords & KE \\
\hline Source & SO \\
\hline Organism & OR \\
\hline Reference & RE \\
\hline Authors & AU \\
\hline Title & TI \\
\hline Journal & JO \\
\hline Comment & CO \\
\hline Features & FE \\
\hline Origin & OR \\
\hline
\end{tabular}

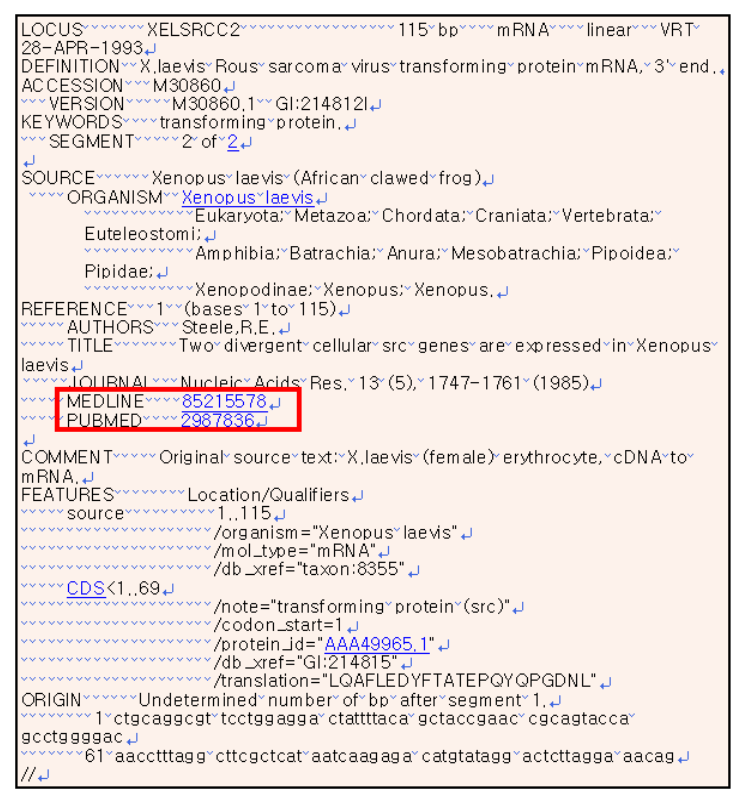

Fig.1. Search Result of Genbank[3]

\subsection{Patent Content Schema}

KISTI's patent content is not classified by bioscientific themes but by grand categories set by the International Patent Classification (IPC). Table 6 illustrates the components of the U.S. patent database among KISTI-provided patent information.

Tab. 6. Schema of patent content

\begin{tabular}{|l|c|}
\hline \multicolumn{1}{|c|}{ Field name } & Code \\
\hline Control Number & CN \\
\hline Title of Invention & TI \\
\hline Country Code & CY \\
\hline Patent Type & PT \\
\hline Document Kind & REG \\
\hline International Patent Classification & IC \\
\hline US Patent Classification & USC \\
\hline Application Number & AN \\
\hline Application Date & AD \\
\hline Publication Number & UN \\
\hline Publication Date & UD \\
\hline Registration Number & RN \\
\hline
\end{tabular}

\begin{tabular}{|l|c|}
\hline Registration Date & RD \\
\hline Priority Number & PRN \\
\hline International Application No. & IAN \\
\hline International Application Date & IAD \\
\hline USC 371 (PCT) Date & \\
\hline USC 102 (e) Date & \\
\hline International Unexamined No. & IUN \\
\hline International Unexamined Date & IUD \\
\hline Drawing & \\
\hline Inventor & IN \\
\hline Inventor Address & INA \\
\hline Inventor Country & INC \\
\hline Applicant & PA \\
\hline Applicant Country & \\
\hline Applicant Address & PAA \\
\hline Agent & AG \\
\hline Abstract & AB \\
\hline Claim & CM \\
\hline Claim Number & BSC \\
\hline Examiner & \\
\hline Related Application Data & DS \\
\hline Designated Country & \\
\hline & \\
\hline
\end{tabular}

\section{DESIGN OF COMMUNITY MODEL}

\subsection{Open Archiving Service}

In an open archiving service, an open web-instead of a closed one-should be utilized so that anyone can access open research/academic information. This study aims to build a platform where anyone can find needed information for free and which serves as an environment for researchers themselves to evolve the community in a constructive way.

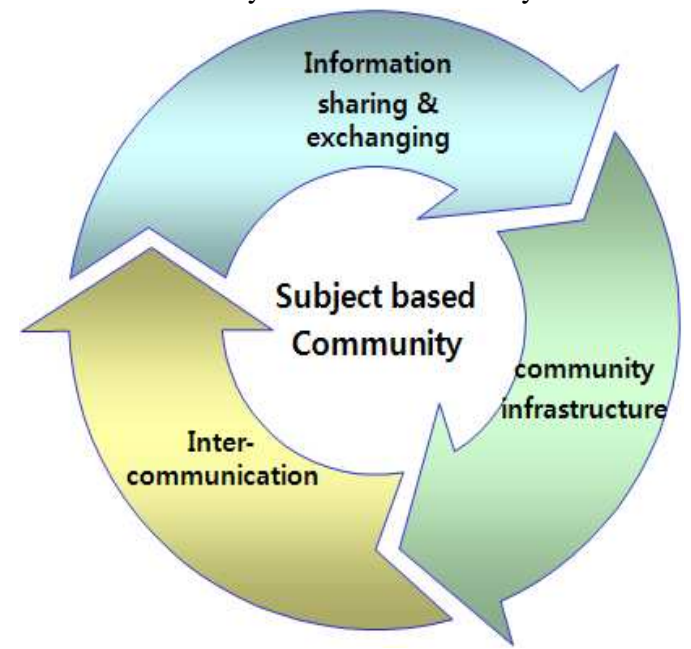

Fig.2. Concept of community model

Open archiving service should not use the closed web but the open web allowing anyone is able to utilize the open R\&D and academic information. The feature that user upload information directly is essential to share data in the web environment(refer to Figure 2). 
Tab. 7. Schema for metadata of shared information

\begin{tabular}{|l|l|l|}
\hline \multicolumn{1}{|c|}{ Column } & \multicolumn{1}{c|}{ Description } & \multicolumn{1}{c|}{ Data type } \\
\hline c_num & control number & int(10) \\
\hline name & title & varchar(50) \\
\hline c_type & type & varchar(20) \\
\hline issn_isbn & ISSN / ISBN & char(10) \\
\hline summary & abstract & text \\
\hline pub_date & publishing date & date \\
\hline lang & language & varchar(10) \\
\hline keywords & keyword & varchar(50) \\
\hline g_code & classification code & char(5) \\
\hline url_addr & source URL & varchar(50) \\
\hline r_doi & source DOI & varchar(20) \\
\hline r_gendate & registration date & date \\
\hline r_moddate & Modification date & date \\
\hline r_generator & registrator & char(10) \\
\hline
\end{tabular}

A database schema (refer to Table 7) for the metadata of shared information is designed to share the location information (URL, e-mail address, etc.) of the original files or to attach the original files by uploading any format of data (refer to Figure 3)[5].

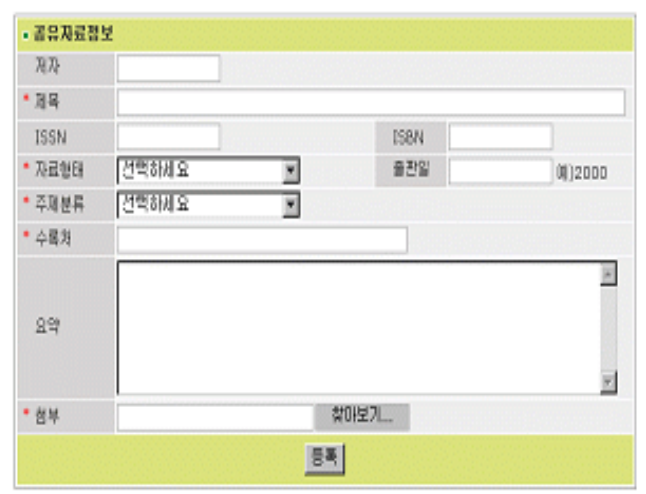

Fig.3. Screen of data uploading

\subsection{Open Access Service}

The design target is that researchers using this community can freely use information produced by the mutual accumulation of bioscience information which is needed to each other while the metadata of journals and articles which are open to access is collected, built, and serviced based on the free usage of information(refer to Table 8)[5].

Table 8. Schema for metadata of article

\begin{tabular}{|l|l|l|}
\hline \multicolumn{1}{|c|}{ Column } & \multicolumn{1}{c|}{ Description } & \multicolumn{1}{c|}{ Data type } \\
\hline c_num & control number & int(10) \\
\hline name & title & $\operatorname{varchar}(50)$ \\
\hline author & first author & $\operatorname{varchar}(20)$ \\
\hline sub_author & correspond author & $\operatorname{varchar}(50)$ \\
\hline j_name & journal name & $\operatorname{varchar}(50)$ \\
\hline j_spec & volume, number & varchar(30) \\
\hline pub_plc & country & varchar(20) \\
\hline pub_org & organization & varchar(50) \\
\hline pub_date & publish date & date \\
\hline lang & language & varchar(10) \\
\hline
\end{tabular}

\begin{tabular}{|l|l|l|} 
summary & abstract & text \\
\hline keywords & keywords & varchar(50) \\
\hline g_code & classification code & char(5) \\
\hline url_addr & source URL & varchar(50) \\
\hline r_doi & source DOI & varchar(20) \\
\hline r_gendate & registration date & date \\
\hline r_moddate & Modification date & date \\
\hline r_generator & registrator & char(10) \\
\hline
\end{tabular}

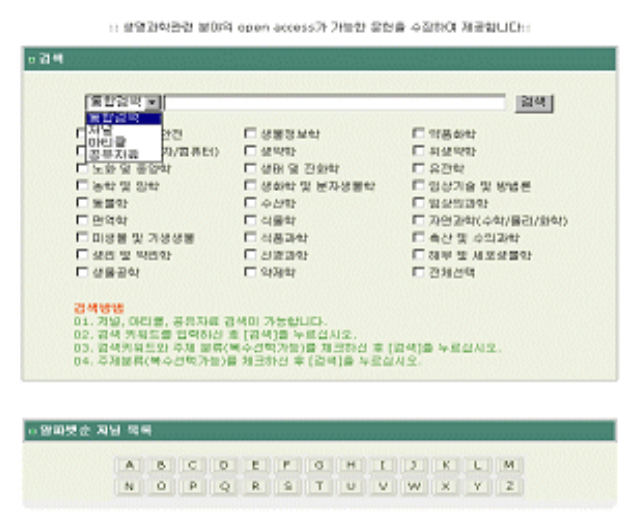

Fig.4. GUI of information retrieval

<Figure 4> is a search GUI to the content of papers (association papers, journal articles, and conference papers, etc.) in bioscience field from the legacy that was provided and built by KISTI and from that was directly uploaded by user in the bioscience. The search function is designed to enable 'search by detail subject', 'search by alphabetic order', 'search by data type', and 'integrated search'[4].

\subsection{Community Management System}

The community management system has features such as screening function for the data registration, modification function of database, and subscriber management function[1][8]. And it is designed to review the registered various research results, to correct if necessary, and ultimately store them in the database as the system configuration in $<$ Figure 5>.

The system also includes the functions of membership level management (i.e. administrator, operator and ordinary members) and statistics (for monitoring how the information is being used). The administrator of the community management system has the rights to register, review, and modify data and to adjust the level of members, and thus the system was developed in a way enabling the administrator to exercise those rights.

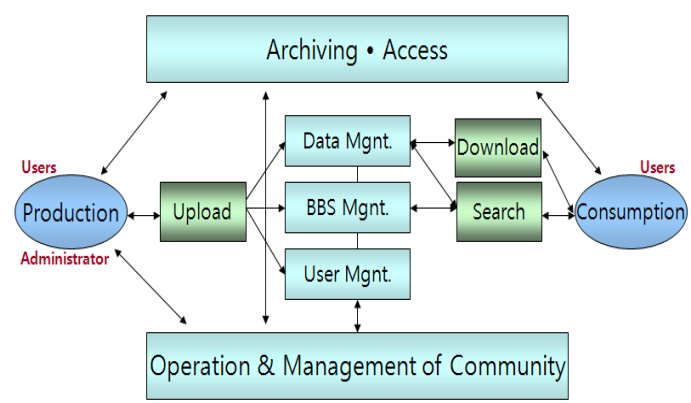

Fig.5. Configuration of community management system 


\section{CONCLUSION}

This study has surveyed and analyzed reference, factual, and patent content that KISTI offers, and, in line with this content, developed a subject-based community model for the field of bioscience. This community model will be modified and improved, based on the feedback of bioscientific researchers and information experts, and become available for domestic researchers of bioscience via the official website of KISTI's comprehensive scientific/technology information service (http://www.ndsl.kr). Once communities for different bioscientific research themes are run in earnest, they will contribute to enhanced research efficiency for researchers by establishing a system for collection and sharing of bioscientific information among researchers, by enabling exchanges of academic information resources, and by providing a virtual laboratory of research and academic activities.

Also, this community model can be utilized further as the basis of future endeavors to interlink KISTI-owned content in other fields of research (e.g. electric/electronic engineering, mechanical engineering, and materials engineering) and build communities for the respective fields as well.

\section{REFERENCES}

[1] arXiv.org e-Print archive website, http://www.arxiv.org

[2] Bu Young Ahn and Chi Pyoung Song, "Construction of the Bibliographic Information Network Prototype for Biology \& Life Science", Journal of Information Management, v.36, n.2., 2005, pp.125-151.

[3] Bu Young Ahn, Jeong Min Han, Chung Shick Oh, and Beom Jong You, "A Study on Update of Bioinformatics Content", Proc. The 21th International CODATA Conference, 2008, pp.61-65.

[4] DOAJ (Directory of Open Access Journal) website, http://www.doaj.org

[5] MODS (Metadata Object Description Schema) website, http://www.loc.gov/standards/mods

[6] KISTI website, http://www.ndsl.kr

[7] Factual Database website, http://fact.kisti.re.kr

[8] OAI (Open Archives Initiative) website, http://www.openarchives.org

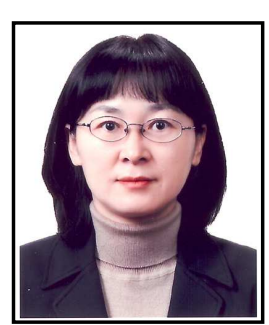

\section{Bu young AHN}

She is senior researcher at the Supercomputing Center, Korea Institute of Science and Technology Information (KISTI), where she does research on eScience, metadata, and factual data. She finished her Ph.D. thesis at the University of Chungnam under professors Eungbong Lee on the Open Community Framework Development based on Web 2.0.

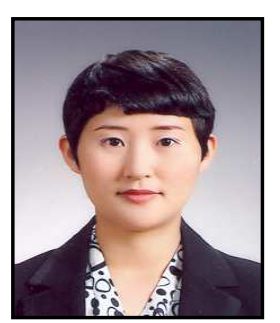

\section{Ji young KIM}

She is senior researcher at the Knowledge Information Center, Korea Institute of Science and Technology Information (KISTI), where she does research on Information service and factual data. She finished her master thesis at the University of Chungnam under professors Kang Seong Kwon on the Reaction mechanisms on Intermetallic compounds.

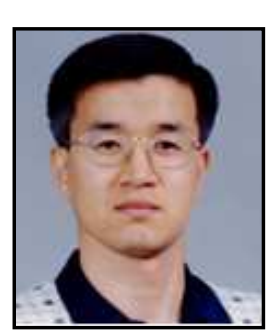

\section{Chung shick OH}

$\mathrm{He}$ is principal researcher at the Information Strategy Team, Korea Institute of Science and Technology Information (KISTI), where his does research information security and ubiquitous. He finished his Ph.D. thesis at the University of Chungbuk under professors Younghwan Cho.

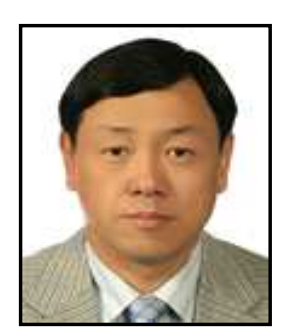

\section{Myung sun LEE}

$\mathrm{He}$ is principal researcher at the Supercomputing Center, Korea Institute of Science and Technology Information (KISTI), where he does research on data processing, network security, and information system security. He finished his Ph.D. thesis at the University of Hannam under professors Jeakwang Lee. 